\title{
Risk factors for cystic fibrosis related liver disease
}

\author{
Eleonora D. T. Fagundes, ${ }^{1}$ Mariza L. V. Roquete, ${ }^{2}$ Francisco J. Penna, ${ }^{3}$ \\ Francisco J. C. Reis, ${ }^{4}$ Eugênio M. A. Goulart, ${ }^{5}$ Cristiano G. Duque ${ }^{6}$
}

\begin{abstract}
Objective: To identify the risk factors for cystic fibrosis related liver disease.

Methods: Ten patients out of a total of 106 patients regularly followed-up during 1999 met the clinical, biochemical and/or ultrasound criteria for liver disease (9.4\%). Using information from the admissions records at the service, we collected data on demography, genotype, age and manifestations at diagnosis of cystic fibrosis, nutritional status and laboratory findings. Variables associated with liver disease were initially identified by the Kaplan-Meier method. Those factors that were significant in the univariate analysis were included in the multivariate analysis by means of a Cox regression model.
\end{abstract}

Results: Under univariate analysis the following factors were associated with liver disease: male sex, age at diagnosis of cystic fibrosis, pancreatic insufficiency, z score for weight at admission, Shwachman score and biochemistry at admission. After adjustment by Cox model, two variables were independently associated with liver disease: Shwachman score $(p=0.0057)$ and age at diagnosis of cystic fibrosis $(p=0.014)$.

Conclusions: The risk of developing liver disease is higher among patients diagnosed at an early age and those with worse clinical status as assessed by the Shwachman score, indicating that liver involvement might be part of a more severe form of the condition. These patients merit greater attention in terms of screening for liver disease and should be given treatment with ursodeoxycholic acid earlier in the event of abnormal findings.

J Pediatr (Rio J). 2005;81(6):478-84: Cystic fibrosis, liver disease, multivariate analysis.

\section{Introduction}

Cystic fibrosis (CF) is the most common cause of chronic progressive lung disease and pancreatic insufficiency in childhood. As the survival of cystic fibrosis patients has progressively improved, there has also been an increase in the prevalence liver disease among them.

1. MD. Pediatrician, Universidade Federal de Minas Gerais (UFMG), Belo Horizonte, MG, Brazil.

2. MD. Assistant professor, Department of Pediatrics, Medicine school, UFMG, Belo Horizonte, MG, Brazil.

3. Full professor, Department of Pediatrics, Medicine school, UFMG, Belo Horizonte, MG, Brazil.

4. Assistant professor, Department of Pediatrics, Medicine school, UFMG, Belo Horizonte, MG, Brazil.

5. Professor, Department of Pediatrics, Medicine school, UFMG, Belo Horizonte, MG, Brazil.

6. Physician, Medicine school, UFMG, Belo Horizonte, MG, Brazil.

Manuscript received Jan 17 2005, accepted for publication Jun 152005.

Suggested citation: Fagundes ED, Roquete ML, Penna FJ, Reis FJ, Goulart EM, Duque CG. Risk factors for cystic fibrosis related liver disease. J Pediatr (Rio J). 2005;81:478-84.
Liver disease is considered a serious complication of CF and can limit the prognosis and quality of life of patients who are affected. ${ }^{1}$ In general the complications of liver disease contribute to an increase in morbidity, although the main cause of death continues to be respiratory failure. On the other hand, with the launching of new drugs, such as ursodeoxycholic acid (UDCA), which apparently delays the course of hepatic disease, it became relevant to better understand the condition, in order to make earlier diagnosis and to improve prognosis of these patients. ${ }^{2,3}$

It is intriguing that liver disease does not occur in all cystic fibrosis patients since all of them have abnormal CFTR (cystic fibrosis transmembrane regulator) in their biliary trees. 4

The relation between CFTR genotype and phenotype with pancreatic insufficiency is well established. However, no mutation of the gene that is specific to liver disease has yet been demonstrated. 5,6 There are indications that other genetic and environmental factors may influence the severity 
of the disease in different patients with the same CF genotype, such as sex, race, history of meconium ileus and nutritional, pulmonary and pancreatic status. ${ }^{7,8}$ The spectrum of this disease is probably the result of differences between the contributions of diverse factors, of the relative severity of each of these, the time of exposure and the impact of other, as yet unknown, factors. ${ }^{4}$

The objective of this study is to determine possible risk factors associated with the development of CF-associated liver disease.

\section{Materials and methods}

This was a longitudinal study, employing the existing protocol of the Cystic Fibrosis Clinic at the Hospital das Clínicas, Universidade Federal de Minas Gerais. The diagnoses of the $106 \mathrm{CF}$ patients had been confirmed by a concentration of chlorine in sweat of $60 \mathrm{mEq} / \mathrm{l}$ or more on at least two separate occasions prior to December 1998. The frequency of consultations at the clinic varied from a minimum of four times a year to up to once a month in the case of patients with more severe clinical status. The mean follow-up period was $5.9 \pm 3.8$ years, with a median of 5.4 years.

The clinical characteristics of this patient sample can be observed in Table 1.

Table 1 - Clinical and demographic characteristics of patients followed at the Cystic Fibrosis Clinic, Hospital das Clínicas

\begin{tabular}{lc}
\hline $\begin{array}{l}\text { Number of cases } \\
\text { Age (years) }\end{array}$ & 106 \\
$\quad$ Median of 9.6 (ranging from 7 months to 24 years) \\
Sex \\
$\quad$ Male/female n (\%) \\
Race & $54 / 52(51 / 49)$ \\
$\quad$ Caucasian/non-caucasian n (\%) & \\
Pancreatic insufficiency n $\%$ ) & $48 / 58(45 / 55)$ \\
Meconium ileus $n(\%)$ & $65(61.3)$ \\
Z-score for weight <-2* & $14(13.2)$ \\
Z-score for height < -2* & $17 \%$ \\
Shwachman score & $20 \%$ \\
$\quad$ Mean/median & \\
$<70 \%$ & $83 \pm 3 / 86$ \\
\hline
\end{tabular}

* At first visit for patients under 18 years-old.

The criteria used to define a diagnosis of CF-associated liver disease were based on clinical, biochemical and/or ultrasound findings. Clinical examination findings were considered abnormal when a palpable spleen and/or hepatomegaly were observed, this last defined as the presence of a firm palpable liver more than $2.5 \mathrm{~cm}$ from the right costal margin. Abnormal biochemistry was defined as a persistent and significant increase, of at least 1.5 times the upper limit of the reference range, of at least two enzymes (AST - aspartate aminotransferase, ALT - alanine aminotransferase, AP - alkaline phosphatase, GGT - gammaglutamyltranspeptidase), for a period of more than six months. Ultrasound abnormalities were defined as the presence of a liver of abnormal size, altered hepatic parenchyma and edge of the liver, splenomegaly and signs of portal hypertension (5). In patients with clinical laboratory and/or ultrasound findings suggestive of liver involvement, other causes of liver disease were excluded, such as Wilson's disease, hepatitis B and C, $\alpha 1$-antitrypsin deficiency and autoimmune hepatitis.

The following risk factors possibly associated with the development of CF-associated liver disease were investigated: sex, race, screening for the most common genetic mutations ( $\Delta \mathrm{F} 508, \mathrm{G} 542 \mathrm{X}, \mathrm{G} 551 \mathrm{D}, \mathrm{R} 553 \mathrm{X}$ and $\mathrm{N} 1303 \mathrm{~K}$ ), history of meconium ileus, age at CF diagnosis, sweat chloride concentration, nutritional status (birth weight, z-score for weight and stature at registration with the clinic, based on the National Center for Health Statistics [NCHS] curves), fecal fat content, pancreatic insufficiency, Shwachman score and biochemical tests at registration with the clinic. The Shwachman-Kulczycki score was conceived as an aid to determining the severity of the disease and the patient's response to therapy. The score is obtained by assessing four categories: 1) general activity; 2) findings from physical examination; 3) findings from thoracic radiology and 4) nutritional status. Each category has a maximum score of 25 , making a total of 100 points. The patient's condition is considered excellent if the score is above 85 points; good, between 71 and 85; medium, between 56 and 70; moderate, between 41 and 55; and severe, when less than or equal to 40 points. ${ }^{9}$

A univariate analysis was initially performed, using Kaplan-Meier product-limit estimation survival analysis. ${ }^{10}$ Survival curves were calculated using KMSURV ${ }^{11}$ for each predictive variable (univariate model). Differences between the group with and the group without liver disease were assessed using the log rank test. Date of birth was considered time zero. The variable time up to development of the first signs of liver disease was defined as continuous and time was measured in years. All continuous variables were categorized for univariate analysis, by means of the cutoff points traditionally employed in clinical practice (birth weight of $2,500 \mathrm{~g}, \mathrm{z}$-score of -2 for weight or stature, fecal fat content of $3 \mathrm{~g} / 24 \mathrm{~h}$ ). In the case of variables such as age at CF diagnosis, sweat chloride concentration and Shwachman score, which have no classical cutoff points, categories were defined according to which value produced most statistical significance in the log rank test, i.e. the point that best differentiated patients with from patients without liver disease.

The Cox regression model ${ }^{12}$ was employed for the multivariate analysis used to identify variables independently associated with the adverse event and to estimate the relative risks of liver disease occurring. Variables with $p<0.25$ in the univariate analysis were included in the multivariate analysis. After obtaining the predictive variables 
from the final model, the presence of interactions was tested for. No variable included in the multivariate analysis violate Cox's assumption of proportionality.

The study was approved by the Committee for Ethics in Medical Research at UFMG. Consent to participate in the study was obtained from parents guardians and/or the patients themselves.

\section{Results}

Ten $(9.4 \%)$ of the 106 CF patients studied exhibited clinical, biochemical and/or ultrasound findings compatible with CF related liver disease. Their clinical characteristics can be observed in Table 2 .

Table 2 - Characteristic of patients with liver disease associted to $\mathrm{CF}$

\begin{tabular}{lc}
\hline Number of patients (\%) & $10(9.4)$ \\
Age (years) & $7.7 \pm 6.4 /$ median 5.7 \\
Sex male/female & $9 / 1$ \\
Race caucasian/non-caucasian & $6 / 4$ \\
Meconium ileus & 0 \\
Neonatal cholestasis & 1 \\
Pancreatic insufficiency & 9 \\
Z-score for weight $<-2 *$ & 4 \\
Z-score for height $<-2 *$ & 3 \\
Shwachman score $<70$ & 3 \\
Ultrasound findings & 10
\end{tabular}

* At first visit.

\section{Univariate analysis}

Table 3 contains the results of the univariate analysis with probabilities of liver disease free survival for the variables investigated together with their respective levels of significance.

The probability of liver disease free survival for patients aged nine months or less at diagnosis (Figure 1) was $76 \% \pm 12$, in contrast with those diagnosed later, for whom the estimated probability was $90 \% \pm 4(p=0.021)$.

The univariate analysis identified Shwachman scores of less than 70 as being predictive of liver disease (Figure 2). The probability of liver disease free survival for patients with scores of 70 or less was $55 \% \pm 14$, whereas for those with scores above 70 , this was $96 \% \pm 3(p=0.0008)$.

Other factors associated with liver disease in the univariate analysis were: male sex, pancreatic insufficiency, z-score for weight below -2 and abnormal biochemistry at registration ( $A S T, A L T, G G T$ and $A P$ ).

\section{Multivariate analysis}

Those variables with $p<0.25$ in the univariate analysis were included in the multivariate analysis. The variables for biochemistry at registration (AST, ALT, GGT and AP) were excluded from the model because of the large number of losses (around 40\%), which meant that the available data might not be representative of the cohort as a whole.

The first model constructed included variables in a dichotomous manner. After adjustment, just the Shwachman score remained a significant predictor of liver disease. The relative risk of patients with Shwachman scores less than or equal to 70 at registration developing CF-associated liver disease was 7.5 times greater than for patients with scores above 70, irrespective of other variables $(p=0.0046$; IC $=1.86-29.92$ ).

A second model was constructed, employing the variables continuously (Table 4 ). Two variables were independently associated with developing liver disease, after tests for interaction: Shwachman score $(p=0.0057)$ and age at CF diagnosis $(p=0.014)$. Since they have a negative coefficient, these variables have an inversely proportional relationship to the risk of liver disease. Thus, the risk of liver disease is higher among patients diagnosed at an early age and those with worse clinical picture assessed by the Shwachman score.

\section{Discussion}

All clinical or epidemiological research is subject to bias at many stages, from collection to final analysis of the data. In studies of CF-associated liver disease, the principal bias may well be in measurement and classification since there are no sensitive markers of liver involvement and diagnostic criteria are not uniform. This study adopted clinical, biochemical and ultrasound findings for the criteria used to define liver disease. Wilschanski et al. ${ }^{7}$ did not include hepatomegaly in their diagnostic criteria because of the possibility of observer bias. Nevertheless, the use of clinical parameters in patient follow-up should be valued. In this study patients were followed by a single researcher for a period of two years. Despite their limitations, these criteria remain the gold standard for the diagnosis of CF related liver disease. 4,13-17 Histopathology was also excluded because of the possibility of sampling errors resulting from the focal character of lesions and it would be unjustifiable to subject asymptomatic patients to the risks inherent in liver biopsy. 13,18

Irrespective of the diagnostic criteria employed, longitudinal follow-up is important for definition of liver disease cases, which should not be labeled as such based on a single assessment because of the intermittent character, not just of biochemistry, but also of ultrasound and physical examination findings. ${ }^{13,15,16}$ For this study, patients were followed prospectively. They exhibited fluctuations in biochemical test results and discrete alterations under physical examination, without, however, ceasing to meet the diagnostic criteria for CF-associated liver disease.

In addition to the limitations involved in measurement and classification, studies of the risk factors for developing CF-associated liver disease have not employed techniques to control for possible confounding factors, whether in the 
Table 3 - Analysis of risk factors of cystic fibrosis with the Kaplan-Meier method

\begin{tabular}{|c|c|c|}
\hline Variable & $\begin{array}{l}\text { Probability of free survival } \\
\text { for liver disease }\end{array}$ & $\mathbf{p}$ \\
\hline Sex & $\begin{array}{l}\text { Male } 79 \% \pm 7 \\
\text { Female } 95 \% \pm 5\end{array}$ & 0.013 \\
\hline Race & $\begin{array}{c}\text { Caucasian } 81 \% \pm 8 \\
\text { Non-caucasian } 91 \% \pm 5\end{array}$ & 0.23 \\
\hline Mutation & $\begin{array}{c}\text { At least one } \Delta \text { F508 allele } 73 \% \pm 14 \\
\text { Others } 88 \% \pm 7\end{array}$ & 0.27 \\
\hline Meconium ileus & $\begin{array}{l}\text { Yes } 100 \% \\
\text { No } 86 \% \pm 4\end{array}$ & 0.59 \\
\hline Age at diagnosis & $\begin{array}{l}\leq 9 \text { months } 76 \% \pm 12 \\
>9 \text { months } 90 \% \pm 4\end{array}$ & 0.021 \\
\hline Chlorine in sweat & $\begin{array}{l}>100 \mathrm{mEq} / \mathrm{l} 80 \% \pm 7 \\
\leq 100 \mathrm{mEq} / \mathrm{l} 95 \% \pm 3\end{array}$ & 0.12 \\
\hline Weight at term* & $\begin{array}{l}<2,500 \mathrm{~g} 83 \% \pm 15 \\
\geq 2,500 \mathrm{~g} 85 \% \pm 5\end{array}$ & 0,77 \\
\hline Weight at admission* (z-score) & $\begin{array}{c}\leq-272 \% \pm 12 \\
>-292 \% \pm 4 \\
\leq-1.88^{+} 74 \% \pm 10 \\
>-1.88^{+} 93 \% \pm 4\end{array}$ & $\begin{array}{c}0.07 \\
0.0426\end{array}$ \\
\hline Height at admission* (z-score) & $\begin{array}{l}\leq-281 \% \pm 8 \\
>-289 \% \pm 5\end{array}$ & 0.32 \\
\hline Fecal fat content* & $\begin{array}{l}>3 \mathrm{~g} / 24 \mathrm{~h} 81 \% \pm 9 \\
\leq 3 \mathrm{~g} / 24 \mathrm{~h} 86 \% \pm 6\end{array}$ & 0.99 \\
\hline Pancreatic insufficiency & $\begin{array}{l}\text { Yes } 76 \% \pm 3 \\
\text { No } 97 \% \pm 3\end{array}$ & 0.018 \\
\hline Shwachman score & $\begin{array}{l}\leq 7055 \% \pm 14 \\
>7096 \% \pm 3\end{array}$ & 0.0008 \\
\hline \multicolumn{3}{|l|}{ Biochemical tests at registration ${ }^{\ddagger}$} \\
\hline AST & $\begin{array}{c}\text { Altered } 51 \% \pm 17 \\
\text { Normal } 93 \% \pm 4\end{array}$ & 0.0094 \\
\hline ALT & $\begin{array}{l}\text { Altered } 44 \% \pm 18 \\
\text { Normal } 92 \% \pm 4\end{array}$ & 0.0024 \\
\hline Alkaline phosphatase & $\begin{array}{c}\text { Altered } 37 \% \pm 19 \\
\text { Normal } 91 \% \pm 5\end{array}$ & 0.0108 \\
\hline GGT & $\begin{array}{c}\text { Altered } 56 \% \pm 25 \\
\text { Normal } 97 \% \pm 3\end{array}$ & 0.01743 \\
\hline
\end{tabular}

AST $=$ aspartate aminotransferase $;$ ALT = alanine aminotransferase; $G G T$ = gamma-glutamyltranspeptidase .

* Other cutoff points were tested, which were non significant as well.

$\dagger$ Corresponds to the 3rd percentile.

‡ Data not available for all patients.

planning or analysis phases. $5,7,19$ With this objective, the present study employed multivariate adjustment.

In addition to contributing to increased morbidity, liver disease has an unfavorable impact on prognosis in CF. ${ }^{20}$ Some studies have indicated that early use of UDCA can retard the development of liver disease. 2,3,21,22 From there springs the need for knowledge of the clinical course of this liver disease and its risk factors.

In this study, the variables age at CF diagnosis and Shwachman score were predictive for the development of liver disease.
Several clinical scoring systems for patients with CF have been developed over recent years. Overall, the most often used is that introduced by Shwachman \& Kulczycki. ${ }^{9}$ The system has proved itself easy to employ and it can be applied to patients of all ages, being considered a good index of prognosis. ${ }^{23,24}$ Nevertheless, its use a predictive factor for liver disease had not yet been described.

When included in the multivariate analysis in a dichotomous manner, the relative risk of patients with Shwachman scores less than or equal to 70 at registration developing CF-associated liver disease was 7.5 times greater 
482 Jornal de Pediatria - Vol. 81, No.6, 2005

Table 4 - Multivariate analysis for the risk of liver disease development: continuous variables

\begin{tabular}{lcccc}
\hline Variable & p & Coefficient & RR & CI 95\% \\
\hline $\begin{array}{l}\text { Shwachman } \\
\begin{array}{l}\text { Age at } \\
\text { diagnosis }\end{array}\end{array}$ & 0.0057 & -0.055 & 0.947 & $(0.91-0.98)$ \\
\end{tabular}

$\mathrm{RR}=$ relative risk $\mathrm{Cl}=$ confidence interval

than for patients with scores above 70, irrespective of other variables. This score essentially assesses the pulmonary and nutritional status of patients. An association between liver disease and mutations considered severe has been described, ${ }^{7}$ suggesting that liver disease is part of a more severe phenotype of the disease. This being so, it would be expected that those patients who present a lower score at registration and consequently have a more severe manifestation of the disease would have a greater probability of developing liver disease.

Several different studies have attempted to correlate age at CF diagnosis with prognosis. Patients diagnosed later have better prognosis than those identified early. ${ }^{25-27}$ On the other hand, this early diagnosis that is implicated in worse prognosis is controlled by many factors, including the severity of symptoms. It is therefore possible to accept that lower age at diagnosis does not lead to greater severity, but that the most severe forms are expressed earlier and are associated with reduced survival. 24

In this study, the age variable remained significant when included in a continuous form $(p=0.014)$, in that the younger the patient at diagnosis, the greater the risk of liver disease. Since early diagnosis is intimately related with the more severe forms of $\mathrm{CF}$, it is possible that liver disease is part of a presentation with worse prognosis, as Williams et al. affirm. ${ }^{20}$

Some factors that are habitually considered to be associated with liver disease, such as sex, pancreatic insufficiency and meconium ileus, were not statistically significant in the multivariate analysis performed in this study.

There are divergences between the many reports in the literature with respect of the risk of liver disease related to male sex. In patient samples described by Scott-Jupp et al. ${ }^{19}$ and Colombo et al. ${ }^{1}$ the risk of liver disease was greater for male patients, which was not repeated in series described by Lindblad et al., ${ }^{3}$ Ling et al. ${ }^{15}$ and Wilschanski et al. ${ }^{7}$ However, these studies did not perform multivariate adjustment.

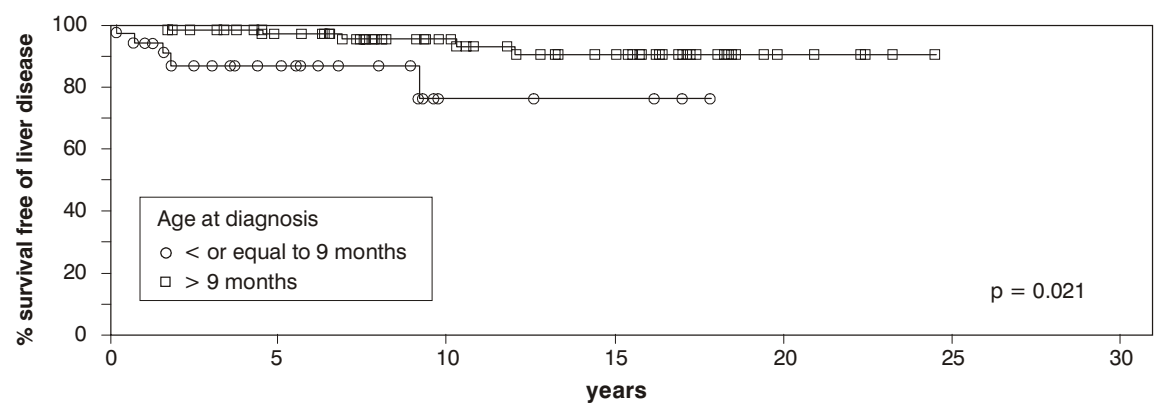

Figure 1 - Free survival curve of liver disease stratified by age at diagnosis: cutoff point of 9 months

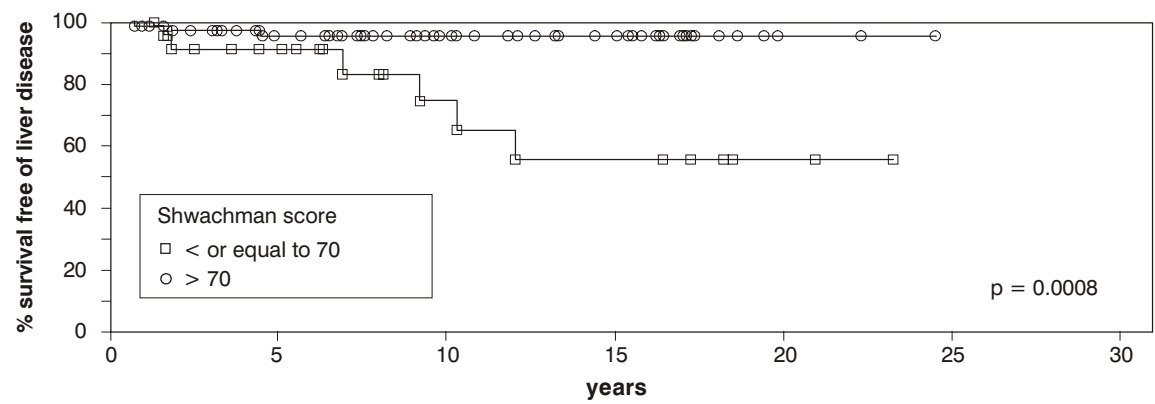

Figure 2 - Free survival curve of liver disease stratified by Shwachman scores: cutoff point of 70 points 
In the current work the univariate analysis indicated that male sex conferred a greater risk than female. However, in the final multivariate model the variable lost its significance in the presence of other factors. Therefore, it is probable that other characteristics of the male patients, such as age at CF diagnosis and the clinical conditions assessed by the Shwachman score have a greater influence on the development of liver disease than sex. It can thus be perceived how complex the diverse factors involved in the development of CF-associated liver disease are.

The importance of nutritional status to the long term survival of patients with CF is well documented.24,28 Nevertheless, several studies have failed to identify differences in nutritional status between patients with and without liver disease. 7,15

In this study the nutritional indicators, birth weight and stature at registration were not statistically significant as factors for predicting liver disease under univariate analysis. Only z-score for weight at registration, split at a cutoff of 1.88, was significant under univariate analysis. Under multivariate analysis, however, this variable too lost significance, since the Shwachman score also includes nutritional assessment. Thus, when two variables are strongly associated, i.e. contributing the same information, one or both can lose significance in the model employed. 29

Hepatobiliary disease has been reported with greater frequency among patients with pancreatic insufficiency. 5,6,19 In a series described by Wilschanski et al., ${ }^{7}$ the risk of liver disease among patients with pancreatic insufficiency was 1.19 (95\% CI 1.04-3.14). On the other hand, Ling et al. ${ }^{15}$ did not identify the same association, which might be the result of other genetic and environmental factors modifying the final effect.

In this sample, pancreatic insufficiency was a predictive factor for liver disease under univariate analysis. However, since both patients with Shwachman scores less than or equal to 70 and those diagnosed before nine months presented pancreatic insufficiency with greater frequency, under multivariate analysis the factor lost its significance.

Despite advances in knowledge of the genetics of CF, it is not yet possible to predict the disease spectrum by genotype analysis. The correlations between genotype and clinical as manifestations other than pancreatic insufficiency are unpredictable. The majority of studies have failed to demonstrated correlation between specific mutations and the development of CF related liver disease, $3,5,7,15$ although an association with mutations considered more severe have been observed. This being so, other genes or environmental factors may influence or predispose towards liver disease. In this study the presence of the $\Delta \mathrm{F} 508$ did not constitute a predictive factor for liver disease.

Meconium ileus has been associated with increased risk of liver disease. ${ }^{3,5}$ Nevertheless, in the majority of studies there was no multivariate analysis with adjustment for other potential prognostic factors such as age at diagnosis, pancreatic insufficiency and nutritional status. In this study a history of meconium ileus was not predictive of liver disease, corroborating data from previous research. 7,15
The Cystic Fibrosis Foundation in the USA 4 recommends that liver biochemistry be tested (ALT, AST, AP and GGT) at diagnosis and annually. In a longitudinal evaluation by Ling et al., 15 clinical and ultrasound findings were preceded by biochemical alterations in $74 \%$ of cases, i.e. biochemistry was a good predictive factor for development of liver disease. In contrast, Lindblad et al. ${ }^{3}$ did not find significant associations between abnormal biochemical test results at diagnosis and the development of liver disease, particularly for those under three years old. Nevertheless, repeatedly negative biochemical test results were a good negative predictor of advanced liver disease.

The analysis of biochemical factors as prognostic indicators was compromised in this study by the large number of failures to collect data or perform these tests. This is in part the result of their not being carried out for all patients during the early phase of the clinic when liver disease was not routinely screened for in all patients. As a result, the analysis of biochemical factors was prejudiced and could not be included in the final predictive model. Prospective studies are needed to assess their importance to predicting CF related liver disease and to establish the significance of intermittent biochemical abnormalities.

Summing up, under multivariate analysis the following factors were independently associated with an increased risk of liver disease: Shwachman score and age at CF diagnosis. These factors are commonly associated with worse prognosis, providing evidence that liver disease appears to be part of a more severe form of the disease. This being so, those cystic fibrosis patients whose diagnoses are made earlier and have worse clinical status, according to the Shwachman score, merit more attention in terms of screening for liver disease and the earlier institution of UDCA in the event of alterations. Prophylactic use in such situations requires further study.

\section{References}

1. Colombo C, Battezzati PM, Strazzabosco M, Podda M. Liver and biliary problems in cystic fibrosis. Semin Liver Dis. 1998;18: 227-35.

2. Cheng K, Ashby D, Smyth R. Ursodeoxycholic acid in cystic fibrosis related liver disease: a systematic review. J R Soc Med. 1997;90:6-12.

3. Lindblad A, Glaumann H, Stradvik B. A two-year prospective study of the effect of ursodeoxycholic acid on urinary bile acid excretion and liver morphology in cystic fibrosis-associated liver disease. Hepatology. 1998;27:166-74.

4. Sokol RJ, Durie PR. Recommendations for management of liver and biliary tract disease in cystic fibrosis. J Pediatr Gastroenterol Nutr. 1999;28 Suppl:S1-13.

5. Colombo C, Apostolo MG, Ferrari M, Seia M, Genoni S, Giunta A, Sereni LP. Analysis of risk for the development of liver disease associated with cystic fibrosis. J Pediatr. 1994;124:393-9.

6. Duthie A, Doherty DG, Williams C, Scott-Jupp R, Warner JO, Tanner MS, et al. Genotype analysis for $\Delta F 508, G 551 D$ and R553X mutations in children and young adults with cystic fibrosis with or without liver disease. Hepatology. 1992;15:660-4.

7. Wilschanski M, Rivlin J, Cohen S, Augarten A, Blau H, Aviram M, et al. Clinical and genetic risk factors for cystic fibrosis-related liver disease. Pediatrics. 1999;103:52-7.

8. Feranchak AP, Sokol RJ. Cholangiocyte biology and cystic fibrosis liver disease. Semin Liver Dis. 2001;21:471-88.

9. Shwachman H, Kulczycki LL. Long-term study of one hundred five patients with cystic fibrosis. Am J Dis Child. 1958;96:6-15. 
10. Kaplan EL, Meier P. Nonparametric estimation from incomplete observations. J Am Stat Ass. 1958;53:457-81.

11. Campos-Filho N, Franco EL. Microcomputer-assisted univariate survival data analysis using Kaplan-Meier life table estimators. Com Meth Prog Biomed. 1988;27:223-8.

12. Cox DR. Regression models and life-table. J Royal Stat Soc Br. 1972;34:187-220.

13. Fagundes ED, Roquete ML, Penna FJ, Reis FJ, Duque CG. Triagem diagnóstica da hepatopatia da fibrose cística. J Pediatr (Rio J). 2002; 78:389-96.

14. Tanner MS, Taylor CJ. Liver disease in cystic fibrosis. Arch Dis Child. $1995 ; 72: 281-4$

15. Ling SC, Wilkinson AS, Hollman AS, McColl J, Evans TJ, Paton JY. The evolution of liver disease in cystic fibrosis. Arch Dis Child. 1999;81:129-32.

16. Williams SM, Goodman R, Thomson A, McHugh K, Lindsell DR. Ultrasound evaluation of liver disease in Cystic Fibrosis as part of an annual assessment clinic: a 9-year review. Clin Radiol. 2002;57:365-70.

17. Fagundes ED, Silva RA, Roquete ML, Penna FJ, Reis FJ, Goulart EM, et al. Validação do escore ultra-sonográfico de Williams para diagnóstico da hepatopatia da fibrose cística. J Pediatr (Rio J). 2004; $80: 380-6$.

18. Feigelson J, Anagnostopoulos C, Poquet M, Pecau $Y$, Munck A, Navarro J. Liver cirrhosis in cystic fibrosis- therapeutic implications and long term follow up. Arch Dis Child. 1993;68: 653-7.

19. Scott-Jupp R, Lama M, Tanner MS. Prevalence of liver disease in cystic fibrosis. Arch Dis Child. 1991;66:698-701.

20. Williams SG, Hayller KM, Hodson ME, Westaby D. Prognosis in cystic fibrosis. N Engl J Med. 1992;327:1244-5.

21. Colombo C, Battezzati PM, Podda M, Podda M, Bettinardi N, Giunta A. Ursodeoxycholic acid for liver disease associated with cystic fibrosis: a double-blind multicenter trial. Hepatology. $1996 ; 23: 1484-90$
22. van de Meerberg $P C$, Houwen $R H$, Sinaasappel $M$, Heijerman HG, Bijleveld $\mathrm{CH}$, Vanberge-Henegouwen GP. Low dose versus high dose ursodeoxycholic acid in cystic fibrosis related cholestatic liver disease. Scand J Gastroenterol. 1997;32:369-73.

23. Huang NN, Schidlow DV, Szatrowski TH, Palmer J, LarayaCuasay LR, Yeung W, et al. Clinical features, survival rate, and prognostic factors in young adults with cystic fibrosis. Am J Med. 1987;82:871-9.

24. Oliveira MC, Reis FJ, Oliveira EA, Colosimo EA, Monteiro AP, Penna FJ. Prognostic factors in cystic fibrosis in a single center in Brazil: a survival analysis. Pediatr Pulmonol. 2002;34:3-10.

25. Wesley A, Dawson K, Hewitt C, Kerr A. Clinical features of individuals with cystic fibrosis in New Zealand. NZ Med J. 1993; 106:28-30.

26. Gan KH, Geus WP, Bakker W, Lamers CB, Heijerman HG. Genetic and clinical features of patients with cystic fibrosis diagnosed after the age of 16 years. Thorax. 1995;50:1301-4.

27. Gan KH, Veeze HJ, van den Ouweland AM, Halley DJ, Scheffer $H$, van der Hout $A$, et al. A cystic fibrosis mutation associated with mild lung disease. N Engl Med. 1995;333:95-9.

28. Rosenfeld $M$, Davis $R$, FitzSimmons $S$, Pepe $M$, Ramsey $B$. Gender gap in cystic fibrosis mortality. Am J Epidemiol. 1997; 145:794-803.

29. Christensen E. Multivariate survival analysis using Cox's regression model. Hepatology. 1987;7:1346-58.

Correspondence:

Eleonora Druve T. Fagundes

Rua Tenente Anastácio de Moura, 740/801, Santa Efigênia

CEP 30240-390 - Belo Horizonte, MG, Brazil

Tel.: +55 (31) 3287.5176

E-mail: eleonoradruve@uol.com.br 